\title{
Resting Metabolic Rate in Monozygotic and Dizygotic Twins
}

\author{
E. Fontaine, R. Savard, A. Tremblay, J.P. Després, E. Poehlman, C. Bouchard \\ Physical Activity Sciences Laboratory, Laval University Quebec
}

\begin{abstract}
In order to study the influence of heredity on resting metabolic rate (RMR), 20 monozygotic and 19 dizygotic male twin pairs aged 20.6 (SD 2.9) and 21.4 (SD 3.1) years, gave their consent to participate in the experiment. Fat free weight (FFW) was estimated from underwater weighing. RMR was measured by indirect calorimetry using an open circuit system. RMR was expressed as $\mathrm{kJ} \cdot \min ^{-1}, \mathrm{~kJ} / \mathrm{m}^{2} \cdot \mathrm{h}^{-1}, \mathrm{~kJ} / \mathrm{kg} \cdot \mathrm{h}^{-1}$ and $\mathrm{kJ} / \mathrm{kgFFW} \cdot \mathrm{h}^{-1}$. Significant intraclass coefficients were observed in $\mathrm{MZ}$ twins for the different expressions of RMR. The values ranged from $r=0.45(P<0.05)$ to $r=0.81$ $(\mathrm{P}<0.01)$. However, DZ twins demonstrated lower intraclass coefficients for RMR, with a range from $r=0.21$ to $r=0.44$. Significant $(P<0.05) \mathrm{DZ}$ resemblance was revealed only when RMR was expressed as $\mathrm{kJ} \cdot \min ^{-1}$ and $\mathrm{kJ} / \mathrm{kg} \cdot \mathrm{h}^{-1}$. Results of the present study suggest that variations in RMR may have a genetic component. Implications for human energy balance and body fat are discussed.
\end{abstract}

Key words: Twins, Resting metabolic rate, Body fatness, Energy expenditure

\section{INTRODUCTION}

Several theories have been put forward to explain the metabolic basis of obesity. Excess body fat is thought to occur as a result of genetic causes and/or unfavourable lifestyle [14]. From about one fourth to one third of the population variance in adult fatness have been considered to result from inherited biological differences $[1,16,19]$.

Reduced resting metabolic rate (RMR) observed in certain obese subjects [15] could be suggested as one of the factors responsible for the propensity of certain individuals to store body fat. Since RMR can represent more than half of the total daily energy expenditure $[6,14]$, variations in resting metabolic rate have important implication in the normal daily energy needs. Variations of the order of $30 \%$ in RMR, between individuals of same age, sex and weight, have been reported [21]. Several factors such as the ratio of 
lean to fat tissues, ambient and body temperatures, nutritional status and hormonal balance are thought to be implicated in such variations [3]. Moreover, it has been suggested that resting energy expenditure exhibited inherited differences [10], but this phenomenon has not completely been elucidated.

The purpose of the present study was therefore to estimate the genetic effect in RMR with data obtained in male monozygotic (MZ) and dizygotic (DZ) twins.

\section{METHODS}

\section{Subjects}

The twin series of this study included $20 \mathrm{MZ}$ and $19 \mathrm{DZ}$ male twin pairs aged 20.6 (SD 2.9) and 21.4 (SD 3.1) years. Zygosity was established from a questionnaire and from several red blood cell antigen and enzyme markers as well as from A, B and C loci of the HLA system. Eight pairs of MZ twins were physically active; otherwise the remaining subjects were sedentary but healthy subjects.

\section{Measurement of Resting Metabolic Rate}

Experiments were all performed between 0700 and 0800 , after a $12 \mathrm{hr}$ overnight fast. No exercise or participation in sports was allowed for $48 \mathrm{hr}$ before the test. The laboratory temperature was kept at $24-26^{\circ} \mathrm{C}$. After being weighed on a calibrated scale, the subjects reclined comfortably in a chair. Precautions were taken to eliminate external perturbations that could influence the RMR. After a $30 \mathrm{~min}$ rest, the metabolic rate was determined by indirect calorimetry using an open-circuit system. A nose clip was fixed and subject breathed through a mouthpiece. Subjects were given instructions and practice in breathing through the mouthpiece. After 3 min of adaptation, a 5 min sample of expired air was collected and analysed for oxygen and carbon dioxide concentrations (Beckman OM-11 and LB-2). The volume of expired air was determined with a turbine flow meter. This procedure was repeated again with a $5 \mathrm{~min}$ interval between the measurements. The mouthpiece and nose clip were removed between the gas collection. RMR was computed using respiratory quotient and oxygen consumption as described by Lusk [12]. The average of the two measurements was taken as the RMR. Furthermore, in order to ascertain the reliability of RMR, repeated measurements were performed with 13 subjects on two different days.

\section{Fat Free Weight}

In order to evaluate the fat free weight of the subjects, percent body fat was estimated from body density, measured by the hydrostatic weighing technique, using the Siri equation [20]. Pulmonary residual volume was assessed according to the procedures of Wilmore et al [22].

\section{Fat Cell Diameter}

A suprailiac adipose tissue biopsy (100 $\mathrm{mg}$ ) was performed according to the method of Ritthaler et al [17]. Fat cells were isolated using a modification [7] of Rodbell method [18]. Mean fat cell diameter (FCD) was determined using a microscope equipped with a graduated ocular. It was calculated by measuring the diameter of at least 500 cells per subject. The technique has been described elsewhere [7].

\section{Maximal Aerobic Power}

Maximal aerobic power (VO2 max) was measured as an indicator of fitness level. Briefly, VO2 max was determined on an electromagnetically braked cycle ergometer using a progressive test to exhaustion. During the test, oxygen uptake, expiratory volume, respiratory exchange ratio, and heart rate were continuously monitored with an automated opencircuit system previously calibrated with gases of known mixtures.

\section{Statistical Analysis}

The variance components, the $F$ ratio computed from the between-sibship over the within-sibship means of squares as well as the intraclass correlation coefficients were obtained as outlined by Haggard 
[11]. Differences between the two groups were assessed with the Student $t$-test. Comparisons of mean value and tests for the equality of total variance were computed according to procedures described by Christian [5].

\section{RESULTS}

Intraclass reliability coefficient for RMR was determined with 13 individuals on two separate occasions. Day 1 mean and variance for $\mathrm{RMR}$ in $\mathrm{kJ} / \mathrm{kg} \cdot \mathrm{h}^{-1}(3.8 \pm 0.64)$ were not significantly different from day 2 values $(3.8 \pm 0.51)$. The test-retest reproducibility coefficient was highly significant $(r=0.86 ; P<0.01)$.

The descriptive statistics for the samples of $\mathrm{MZ}$ and $\mathrm{DZ}$ twins are given in Table 1.

Table 1 - Descriptive Statistics for a Sample of $20 \mathrm{MZ}$ and $19 \mathrm{DZ}$ Pairs of Male Twins

\begin{tabular}{|c|c|c|c|c|c|}
\hline \multirow{2}{*}{$\begin{array}{l}\text { Variables } \\
\text { Age }(\mathrm{yr})\end{array}$} & \multicolumn{2}{|c|}{$\begin{array}{c}\mathrm{MZ}(\mathrm{N}=40) \\
\overline{\mathrm{X}}(\mathrm{SD})\end{array}$} & \multicolumn{2}{|c|}{$\begin{array}{c}\mathrm{DZ}(\mathrm{N}=38) \\
\overline{\mathrm{X}}(\mathrm{SD})\end{array}$} & \multirow{2}{*}{$\frac{\begin{array}{c}\text { t-test } \\
(\mathrm{P})\end{array}}{\mathrm{ns}}$} \\
\hline & 20.6 & (2.9) & 21.4 & ( 3.1$)$ & \\
\hline Weight $(\mathrm{kg})$ & 65.7 & $(7.8)$ & 66.4 & $(8.6)$ & ns \\
\hline Height $(\mathrm{cm})$ & 174.3 & $(5.9)$ & 173.4 & $(8.6)$ & ns \\
\hline Percent fat $(\%)$ & 11.3 & $(4.1)$ & 12.3 & $(6.7)$ & ns \\
\hline Adipocyte diameter $(\mu \mathrm{m})$ & 79.2 & $(9.7)$ & 82.9 & $(14.4)$ & ns \\
\hline $\mathrm{VO}_{2} \max (\mathrm{ml} / \mathrm{kg})$ & 53.2 & $(4.2)$ & 50.5 & $(6.6)$ & $P<0.05$ \\
\hline $\mathrm{V}_{2} \max (1 / \mathrm{min})$ & 3.43 & $(0.47)$ & 3.31 & $(0.44)$ & ns \\
\hline
\end{tabular}

Mean percent body fat reaches $11.3 \%$ and $12.3 \%$ in the $\mathrm{MZ}$ and $\mathrm{DZ}$, respectively indicanting that the sample was rather lean. Table 2 presents the twin type differences between the means as well as the total variances for all RMR values. Significant differences between the two groups were observed for all RMR mean values $(P<0.01)$. However, total variance was comparable in each twin type.

Table 3 describes the results of the twin data in terms of analysis of variance and intraclass correlation coefficient for the various RMR expressions. In the $M Z$ twins, ANOVA revealed significant within-pair resemblances $(P<0.05)$. In the $\mathrm{DZ}$ twins, the $F$ ratios were lower and significant only when $R M R$ was expressed in $\mathrm{kJ} / \mathrm{kg} \cdot \mathrm{h}^{-1}$ $(\mathrm{P}<0.05)$.

The Figure illustrates the covariation between the members of each twin pair for $\mathrm{RMR}$ expressed as $\mathrm{kJ} / \mathrm{m}^{2} \cdot \mathrm{h}^{-1}$ and $\mathrm{kJ} / \mathrm{kg} \cdot \mathrm{h}^{-1}$. Interclass correlations reached 0.69 and 0.63 in $\mathrm{MZ}$ vs 0.28 and 0.44 in $\mathrm{DZ}$ twins.

\section{DISCUSSION}

Significant differences in mean RMR values between the two twin samples were obtained. These differences could probably not be accounted for by methodological variations since intraclass reliability coefficient for the RMR measurement was quite high. Moreover, in our laboratory, a subgroup of 6 subjects were measured on 5 consecutives days for RMR and no significant differences in RMR were found between the 5 days [9]. One possibility to account for these differences, but a rather remote one, comes from the fact that the MZ twins had a slightly higher $\dot{V O} 2 \mathrm{max} / \mathrm{kg}$ value which could reflect differences in activity pattern and bear consequences on RMR. In a previous study, we have demonstrated a higher RMR in a group of highly trained individuals when compared 


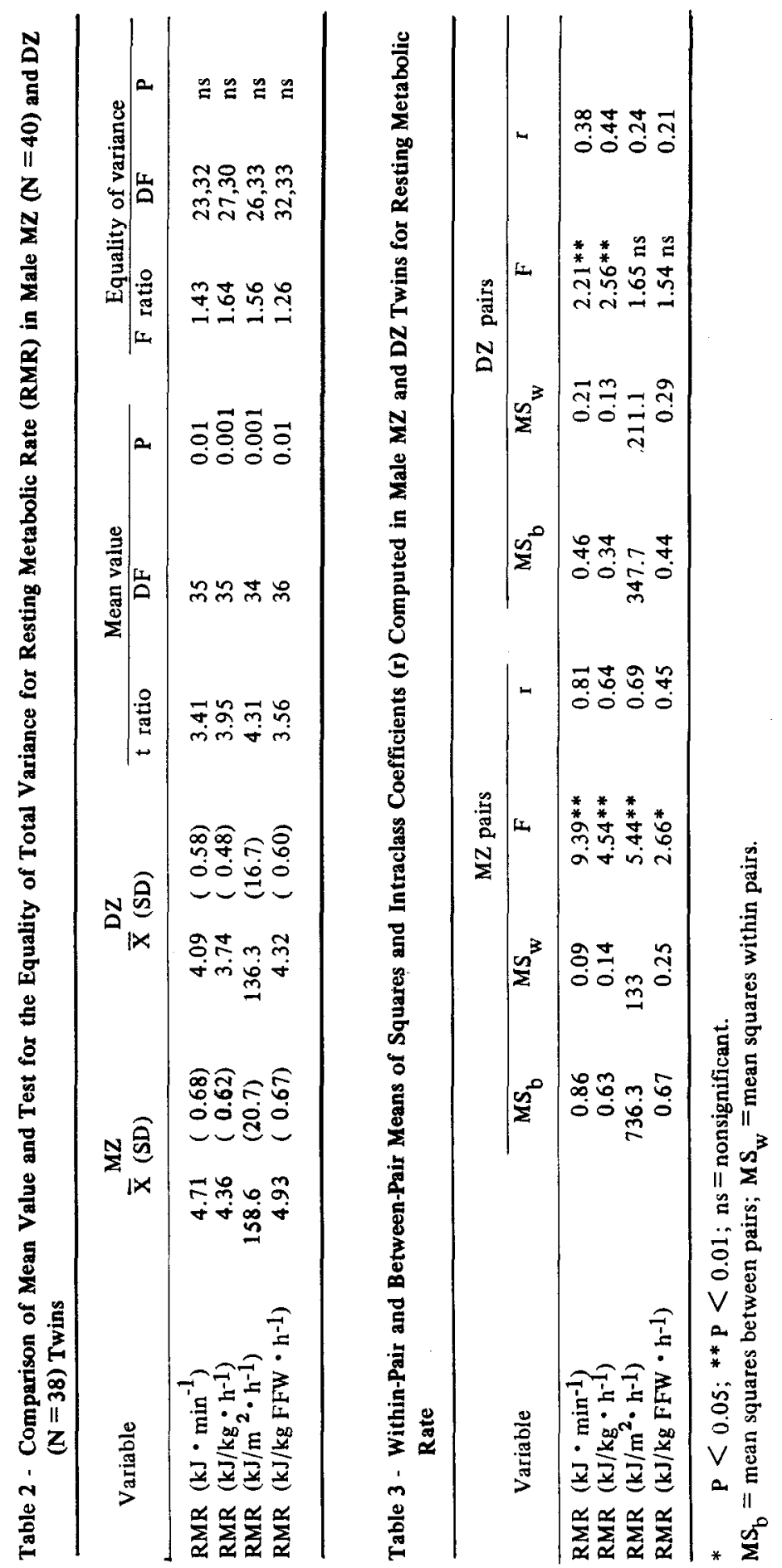



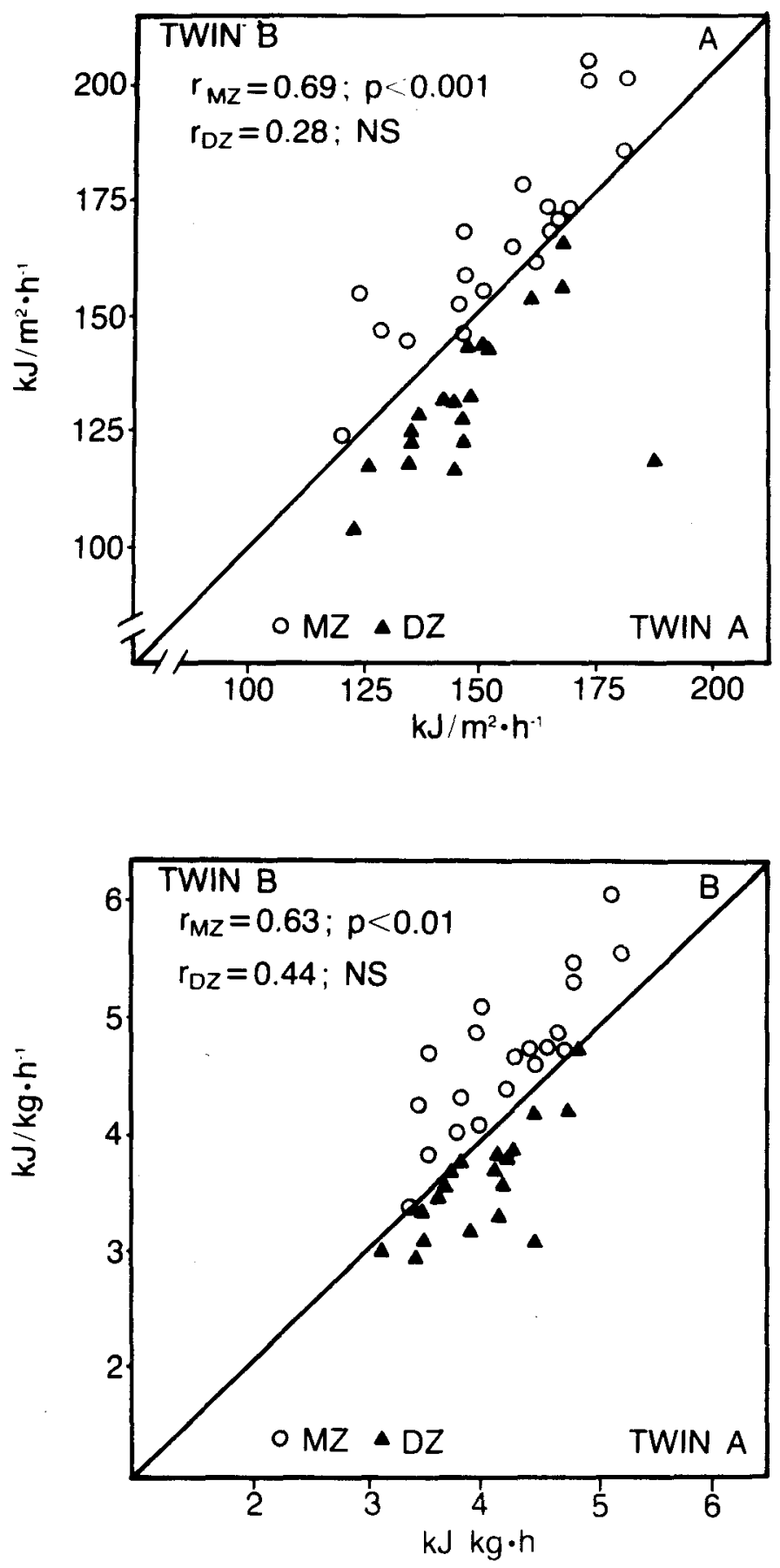

Figure - RMR values $\mathrm{kJ} / \mathrm{m}^{2} \cdot \mathrm{h}^{-1}$ (1a) and $\mathrm{kJ} / \mathrm{kg} \cdot \mathrm{h}^{-1}(1 \mathrm{~b})$ in $20 \mathrm{MZ}$ and $19 \mathrm{DZ}$ twin pairs. For $\mathrm{MZ}$ twins, the lowest of the two RMR values is plotted along the abcissa, for $D Z$ twins the lowest value is plotted along the ordinate. Thus, $\mathrm{MZ}$ pairs are arranged above, $\mathrm{DZ}$ pairs below the 45 line. Interclass coefficients are reported. 
The present study suggests that heredity may contribute significantly to variations in RMR. Intraclass coefficients computed for different expressions of RMR ranged from 0.45 to 0.81 in $\mathrm{MZ}$ twins and from 0.21 to 0.44 in $\mathrm{DZ}$ twins. Relatively few studies are available concerning the genetic influence on RMR. Griffith and Payne [10] demonstrated that children of obese parents had a lower energy expenditure when compared to children of lean parents. Such results suggest the presence of a metabolic difference that is not secondary to an obese state. Miller and Parsonage [15] have obtained results that corroborated these findings. In fact, they have observed that certain obese individuals, under a strict diet, encountered great difficulties in decreasing their fat stores. These authors suggested that a lower resting energy expenditure component could be implicated in this phenomenon. Thus, the resemblance observed here for RMR in MZ twins in contrast to $\mathrm{DZ}$ twins could contribute, at least in part, to variations observed in body fatness.

Studies on human have indicated that genetic variation contributes to interindividual differences in body fatness [16,19]. In our laboratory, skinfold thicknesses as well as body composition measurements, using an underwater weighing technique, have been used in the study of the contribution of heredity on body fatness level. Significant correlations between biologically related individuals have been found when 6 skinfolds thicknesses were assessed in 481 parents and children of 114 families [19]. Moreover, body density was significantly correlated in biological sibs, DZ and MZ twins, while it was not in adoptive sibs [2]. Brook et al [4] have obtained high heritability estimates when measuring triceps and subscapular skinfolds thicknesses in $\mathrm{MZ}$ and $\mathrm{DZ}$ twins above the age of 10. Furthermore, Després and Bouchard [7] found significant intraclass coefficients in male $\mathrm{MZ}$ twins for mean adipocyte diameter, basal and stimulated lipolysis. All these data support the contention that there is a significant level of resemblance in fat characteristics for individuals genetically related by descent.

It is interesting to observe that, in the present experiment, RMR expressed as $\mathrm{kJ} /$ $\mathrm{kg} \cdot \mathrm{h}^{-1}$ was negatively correlated with percent body fat and fat cell diameter, ie, $\mathrm{r}=$ $=-0.44$ and $r=-0.52$, respectively $(P<0.01$; results not shown). Similar results have been obtained in a previous experiment [8]. These results, along with the evidence of a genetic component in body fatness and in RMR values, suggest that, in a population of healthy persons, a low RMR may predispose some individuals to accumulate body fat.

In summary, higher intraclass coefficients were observed in a population of male $M Z$ twins as compared to DZ twins. Even though a difference between the mean RMR values by twin type was found, the data suggest a meaningful contribution of heredity in RMR measurements. Moreover, a significant and negative relationship was observed between RMR and percent body fat. Taken together, these observations suggest that some individuals are possibly characterized by a greater metabolic efficiency, as revealed by a low RMR, which could lead more easily to a positive caloric state. On the other hand, having inherited a high RMR could function as a protective mechanism against the accumulation of body fat.

Acknowledgments. The authors are grateful to Henri Bessette and Claude Leblanc for their assistance, This study was supported by FCAC-Québec (EQ-1330) and NSERC (A-8150). 


\section{REFERENCES}

1. Bouchard C (1980): Transient environmental effects detected in sibling correlations. Ann Hum Biol 7:89-92.

2. Bouchard C, Savard R, Després JP, Tremblay A, Leblanc C (1985): Body composition in adopted and biological siblings. Hum Biol (in press).

3. Bray GA, Atkinson RL (1977): Factors affecting basal metabolic rate. Prog Fd Nutr Sci 12:395403.

4. Brook CGD, Huntley RMC, Slack J (1975): Influence of heredity and environment in determination of skinfold thickness in children. Brit Med J 2:719-721.

5. Christian JC (1979): Testing twins means and estimating genetic variance. Basic methodology for the analysis of quantitative twin data. Acta Genet Med Gemellol 28:35-40.

6. Danforth E (1981): Dietary induced thermogenesis: control of energy expenditure. Life Sci 28:1821-1827.

7. Després JP, Bouchard C (1984): Monozygotic twin resemblance in fatness and fat cell lipolysis. Acta Genet Med Gemellol 33:472-485.

8. Fontaine E, Savard R, Tremblay A, Després JP, Poehlman E, Bouchard C(1984): Resting metabolic rate in exercise-trained and untrained subjects: relationship with body fatness (Unpublished).

9. Fontaine E, Nadeau A, Tremblay A (1983): Acute effect of exercise on resting metabolic rate and thermic effect of glucose. Can J Appl Sport Sci 8:220 (Abstract).

10. Griffiths M, Payne PR (1976): Energy expenditure in small children of obese and non obese parents. Nature 260:698-700.

11. Haggard EA (1958): Intraclass Correlation and the Analysis of Variance. New York: The Dryden Press.

12. Lusk G (1928): The Elements of Science of Nutrition, Philadelphia: Saunders.

14. Miller DS (1979): Thermogenesis and energy needs. Z. Ernährungswiss Suppl 23:85-91.

15. Miller DS, Parsonage S (1975): Resistance to slimming adaptation or illusion? Lancet 773-775.

16. Mueller WH (1983): The genetics of human fatness. Yearb Phys Anthropol 26:215-230.

17. Ritthaler F, Weis $M$, Hack F, Weicker $H(1980)$ : Two biopsy techniques for human subcutaneous adipose tissue. Int J Sports Med 1:50-51.

18. Rodbell M (1964): Metabolism of isolated fat cells. J Biol Chem 239:375-380.

19. Savard R, Bouchard C, Leblanc C, Tremblay A (1983): Familial resemblance in fatness indicators. Ann Hum Biol 10:111-118.

20. Siri WE (1956): The gross composition of the body. Adv Biol Med Phys 4:239-280.

21. Warwick PM, Toft R, Garrow J (1978): Individual variation in energy expenditure. In GA Bray (ed): Recent Advances in Qbesity Research (Vol. 2). London: Newman.

22. Wilmore JH, Vodak PA, Parr RB, Girandola RN, Billing JE (1980): Further simplification of a method for determination of residual lung volume. Med Sci Sports Exerc 12:216-218.

Correspondence: Dr. Claude Bouchard, Physical Activity Sciences Laboratory, PEPS - Laval University Ste-Foy, Québec, Canada GIK 7P4. 